Article

\title{
Crowdsourced Quantification and Visualization of Urban Mobility Space Inequality
}

\author{
Michael Szell 1,2,3,4 \\ ${ }^{1}$ Center for Network Science, Central European University, 1051 Budapest, Hungary; E-Mail: szellm@ceu.edu \\ 2 Center for Complex Network Research, Northeastern University, 02115 Boston, USA \\ ${ }^{3}$ Complexity Science Hub Vienna, 1080 Vienna, Austria \\ ${ }^{4}$ MTA KRTK Agglomeration and Social Networks Lendület Research Group, Centre for Regional Studies, Hungarian Academy \\ of Sciences, 1094 Budapest, Hungary
}

Submitted: 2 October 2017 | Accepted: 18 December 2017 | Published: 29 March 2018

\begin{abstract}
Most cities are car-centric, allocating a privileged amount of urban space to cars at the expense of sustainable mobility like cycling. Simultaneously, privately owned vehicles are vastly underused, wasting valuable opportunities for accommodating more people in a livable urban environment by occupying spacious parking areas. Since a data-driven quantification and visualization of such urban mobility space inequality is lacking, here we explore how crowdsourced data can help to advance its understanding. In particular, we describe how the open-source online platform What the Street!? uses massive user-generated data from OpenStreetMap for the interactive exploration of city-wide mobility spaces. Using polygon packing and graph algorithms, the platform rearranges all parking and mobility spaces of cars, rails, and bicycles of a city to be directly comparable, making mobility space inequality accessible to a broad public. This crowdsourced method confirms a prevalent imbalance between modal share and space allocation in 23 cities worldwide, typically discriminating bicycles. Analyzing the guesses of the platform's visitors about mobility space distributions, we find that this discrimination is consistently underestimated in the public opinion. Finally, we discuss a visualized scenario in which extensive parking areas are regained through fleets of shared, autonomous vehicles. We outline how such accessible visualization platforms can facilitate urban planners and policy makers to reclaim road and parking space for pushing forward sustainable transport solutions.
\end{abstract}

\section{Keywords}

big data; bin packing; crowdsourcing; data visualization; mobility; OpenStreetMap; sustainable transport; transport justice; urban space inventory; volunteered geographical information

\section{Issue}

This article is part of the issue "Crowdsourced Data and Social Media for Participatory Urban Planning", edited by Bernd Resch (University of Salzburg, Austria), Peter Zeile (Karlsruhe Institute of Technology, Germany) and Ourania Kounadi (University of Salzburg, Austria).

(C) 2018 by the author; licensee Cogitatio (Lisbon, Portugal). This article is licensed under a Creative Commons Attribution 4.0 International License (CC BY).

\section{Introduction}

From a geometric perspective, urbanization is a process that packs large numbers of individuals into a limited amount of space. Over time, all urban space is zoned and allocated for human activities: dwelling, industry, business, recreation, and mobility. Due to this natural confinement and densification, urban public space has be- come highly contested, especially transport infrastructure, including roads, parking, sidewalks, tram tracks, and bicycle lanes (Gössling, 2016). Historically, between these mobility spaces, the car has been given highest priority, leading to car-centric cities, starting with its advent in the early 20th century (Norton, 2007). In the US, the initial medium in the struggle for transport space was language: new terms like "pleasure traffic", "joy rider", 
and "jay walker" shaped the public discourse, but by the 1930s, street equilibrium had been decided towards cars, paving the way for the "supremacy of automobiles" (Norton, 2007). Consequently, the automobile industry has systematically bought up and dismantled public street car systems (Urry, 2013) and demolished disadvantaged, usually black, neighborhoods to create space for cars with the help of public officials. One famous example includes the construction of the Eisenhower National System of Interstate and Defense Highways, which considerably improved travel connections between cities but destroyed and fragmented living space within them (Mohl, 2002). Thus, the evolution towards car-centric cities is a history paved with institutionalized racism and social injustice-a process that is repeated in non-Western parts of the world today (Martin, 2007).

\subsection{The Spatial Inefficiency of Cars}

Adding to the social injustice of car-centric policies, which are still in place today and continue to create divides between people who can and cannot afford a car, cultivating the automobile as a main mode of transportation has a number of sustainability issues. We first highlight those issues that relate to mobility space.

Due to individualistic, wasteful use of resources, privately owned cars are not used between $95 \%$ and $97.5 \%$ of the time (Bates \& Leibling, 2012; Organisation for Economic Co-operation and Development [OECD], 2015; Weigele, 2014). For example, privately owned cars in Berlin are used on average 36 minutes per day. In other words, they are not used for 1404 minutes per day, or $97.5 \%$ of the time (Weigele, 2014). These low usage rates imply that at a typical point in time, out of the 1.2 million registered cars in Berlin, only 30,000 are actively used on the road, while the rest is parked. These parked cars take up massive urban space amounting to around 14 million square meters, the area of 64,000 medium-sized playgrounds $(15 \mathrm{~m} \times 15 \mathrm{~m})$ or over 4 Central Parks. The same argument holds for London (Bates \& Leibling, 2012) and other cities (Shoup, 2005). Further accessible estimations of these massive areas include: the total of all off-street parking spaces of the USA is approximately the size of Connecticut (Shoup, 2005); 7 million front plots in Britain have been replaced by parking lots, amounting to around 100 Hyde Parks (Bates \& Leibling, 2012). Such inefficiency comes with exorbitant economic burden-Shoup (2005) estimates free parking in the US to correspond to a yearly public subsidy to car drivers of at least $\$ 127$ billion.

Cars have an average occupancy of 1.5 individuals (Moriarty \& Honnery, 2008). With a dimension of around $8 \mathrm{~m}^{2}$, a car thus requires $5 \mathrm{~m}^{2}$ per person, having a much higher mass-to-seat ratio than bicycles or well-utilized mass transportation. However, the striking space inefficiency of cars comes from heightened demands on infrastructure space, especially parking space (Chester, Fraser, Matute, Flower, \& Pendyala, 2015; Shoup, 2005), and from secondary effects such as increasing transport vol- umes due to urban sprawl (Banister, 2005; Glaeser \& Kahn, 2004; Gössling, 2016; Hutton, 2013). Due to these issues, car-centric cities have decreased benefits from scaling (Louf \& Barthelemy, 2013).

Because automobile infrastructure takes up an excessive amount of urban space, we ask: Do we even know how exactly mobility space is distributed today? If not, can we measure how much more space is allocated to cars than to more sustainable forms of transportation? Is there an "arrogance of space" (Colville-Andersen, 2013), and how can we quantify and help to revert it?

\subsection{Towards a Rigorous, Large-Scale Assessment of Mobility Space Inequality}

Although the car-centricity of today's cities is a leitmotif in the urban transport planning literature (Banister, 2005), the distribution of urban mobility space and its "fairness" has so far not been quantified both rigorously and on a large scale. The quantification problem can be broken down into two steps: 1) Measure the distribution of mobility space between different modes of transportation; 2) Compare the share of allocated space with the modal share. If share of allocated space for one mode of transportation is substantially higher than its modal share, the distribution is unjust, because this mode gets more space than it "deserves" from actual usage.

A first attempt comes from Agentur für clevere Städte (2014), who have studied the distribution of space between cars and bicycles in 200 streets in Berlin. Agentur für clevere Städte found that only $3 \%$ of the streets have bicycle lanes, but $58 \%$ of the total transport space is allocated for cars. With a modal share of $15 \%$, bicycles thus receive considerably less space, while cars, with a modal share of $33 \%$, are vastly over-prioritized. At the same time, being faced with growing bicycle traffic, the study concludes with policy recommendations to extend bicycle infrastructure.

Another, more visual, approach comes from ColvilleAndersen (2014) who has manually assessed the distribution of a few hand-picked intersections, and from visual inspection has indeed concluded an "arrogance of space", i.e., a privileged allocation of urban space to cars at the expense of sustainable forms of mobility such as cycling. Although this first attempt is visually impressive, its methodology does not follow a rigorous assessment of space and is not scalable. In his latest publicized case study, Colville-Andersen (2017) directly compares modal share with space allocation, and finds the imbalance between the two makes the issue particularly pressing: there is a $62 \%$ modal share for bicycles, but only $7 \%$ of mobility space is allocated to them. On top of this, the result is obtained for a particular street segment in Copenhagen which is known for its bicycle-friendly planning culture. If the arrogance of space is already so apparent in Copenhagen, then how bad is the situation in cities of infrastructurally underdeveloped countries like the US? 
Gössling, Schröder, Späth and Freytag (2016) have recently quantified the inequality of urban mobility space scientifically. This study also focuses on a few handpicked intersections as proof of concept in the German city of Freiburg, but uses more rigorous methods involving satellite images and validation through highresolution maps and on-site visits. Like Colville-Andersen (2017), Gössling et al. (2016) find that in their case studies far more space is given to streets and car parking than to bicycle lanes. Similarly, they conclude that pedestrians, on the other hand, receive ample space when compared to their modal share. It is important to note that having space is only a physically necessary, but not a sufficient prerequisite for a form of mobility to work successfully; making cities walkable or bikeable requires a number of conditions to be fulfilled (Speck, 2013).

In this article, we shift the approach from such individual, manual, and thus costly assessment of the distribution of mobility spaces (Colville-Andersen, 2014, 2017; Gössling et al., 2016) to data-driven, crowdsourced measurement. This approach has the benefit of being largescale and inexpensive: it is able to capture entire cities due to the automatized computation of all mobility spaces that have been tagged by millions of users. On the other hand, this method comes with the disadvantage of less rigor than Gössling et al. (2016) due to reporting biases and data quality issues, leading to less accuracy on particular places. Nevertheless, the strength of the method lies in numbers: the statistical accuracy of assessing space inequality increases with scale, while the cost is relatively negligible and scales efficiently with the number of assessed square meters-whether we consider a neighborhood, a city, or a whole urban agglomeration. The focus of this article, however, is not to establish increased correctness in the assessment of mobility space distributions, but to explore advances in visualization, public engagement, and crowdsourced urban planning.

In this article we first present a novel method of collecting and visualizing city-wide mobility spaces for public exploration through an online platform in Sections 2 and 3. This presentation is followed by an analysis of data collected from visitor interactions on the platform in Section 4, providing evidence for a biased perception of mobility space inequality. In Section 5 we add a particular note on how much parking space could be regained if all current cars turned into a shared, public fleet of autonomous vehicles-ignoring the feasibility and unintended consequences of such a scenario. We discuss possible data and design limitations of crowdsourced data and online platforms in Section 6, improvements and synergies between the different assessment methods and their relevance for urban planning in Section 7. Further sustainability issues of cars and their possible solutions are discussed in Section 8.

\section{Visualization of All Parking and Lane Spaces}

To visualize the space requirements of different forms of mobility, with moovel lab we recently developed and launched an interactive online platform, The Mobility Space Report: What the Street! ${ }^{1}$. The idea of the platform is to collect all mobility and parking spaces of a whole city for each type of mobility, and to align these spaces in a visually comparable way. At the same time, the platform makes the "arrogance of space" accessible to a broad public, packing all urban mobility spaces into giant bar charts, reducing the complexity of comparing thousands of shapes to the single dimension of comparing heights. Data for parking and lane spaces originate from OpenStreetMap (OSM), the crowdsourced opencontent alternative to commercial online maps. Due to data availability reasons (see Section 6) only three types of mobility were considered: cars, rails, bicycles.

\subsection{Data Collection, Processing, and Selection}

For each form of mobility the platform deals with two sets of spaces: 1 ) parking spaces; and 2) spaces that are used for movement. In the case of automobiles and bicycles, the parking spaces are encoded by polygons. For all three forms of mobility, the spaces that are used for movement are given by polygonal chains (curves specified by sequences of points) and an optional width. Rail parking consists of service tracks, also encoded by polygonal chains.

All methods of data collection, data wrangling, and the technical implementation of the visualization, including the complete code for back and frontend, are documented and open-sourced. ${ }^{2}$ The whole process is thus completely reproducible, and summarized in the following paragraph. Further technical details can be found in the repository READMEs.

Data collection was a straightforward download, either directly from OSM, or from a content aggregator like Geofabrik. ${ }^{3}$ The geo-data was cropped with the city limits using the OSM-specific tool osmconvert. The cropped data was then loaded into a MongoDB. The raw OSM data consist of a multitude of elements, including nodes, ways, and relations such as traffic lights, forests, or restaurant locations. To filter this data for the relevant car and bike parking structures, the corresponding polygons were identified using the amenity=parking and amenity=bicycle_parking tags, respectively. For car lanes, i.e. roads, all street names were first identified, to only select roads that are searchable by name. Using these names, road spaces were then selected via highway=service $O R$ highway=residential $O R$ highway=primary $O R$ highway=secondary $O R$ highway=tertiary $O R$ highway=unclassified. Bicycle lanes were selected to include only physically separated lanes,

\footnotetext{
$\overline{1}$ https://whatthestreet.moovellab.com

2 https://github.com/moovel/lab-what-the-street

${ }^{3}$ www.geofabrik.de
} 
i.e. lanes that follow best practice implementation (see Section 6.5) using the tags highway=cycleway OR bicycle=designated OR cycleway=track. Rail space used for movement was selected with the tags railway=mode AND (service=crossover OR !service) where mode is one of tram, light_rail, rail, subway, narrow_gauge, funicular, monorail. Parking rail spaces were selected using railway=mode $A N D$ service!=crossover $A N D$ service. A parser was developed to extract all relevant information on number of lanes and widths accounting for inconsistent or ill formatted data, to identify areas correctly. For details on data selection and biases see Section 6 .

\subsection{Parking Space Packing}

Parking spaces come in a variety of scales and shapes, from rectangular lots for single cars to meandering structures that accommodate many thousand vehicles. These shapes are encoded as polygons in OSM. A straightforward way to pack these spaces densely into a rectangular bin is the application of a polygon packing algorithm, solving heuristically the irregular bin packing problem (López-Camacho, Ochoa, Terashima-Marín, \& Burke, 2013). The platform uses the open-source package SVGNest, ${ }^{4}$ which was initially developed for minimizing waste when cutting shapes out of a flat material. Figure 1 (top) shows SVGNest applied to all car parking spaces of the city of Johannesburg (rotated by 90 degrees). Due to restrictions on computational complexity-bin packing is NP-hard (López-Camacho et al., 2013)-SVGNest ran iteratively on randomly partitioned, then re-stitched, subsets of the polygons, fully exhausting them. These technical steps are documented in the corresponding linked source code. The purpose of this auxiliary heuristic is to overcome computational limitations of SVGNest while balancing aesthetics.

Visually, this process leads to the aesthetically pleasing and almost seamless packing of all parking spaces as demonstrated in Figure 1 (top). This rectangle of packed parking spaces can then be directly compared to another rectangle of mobility spaces if it contains objects with the same density.

\subsection{Lane Cutting and Coiling}

For each city and mobility type the platform uses all lane spaces. To make lane space comparable to the corresponding parking space, lanes were coiled and stitched together in a sausage-like tube, shown in Figure 1 (bottom). The displayed thickness is not to scale but was chosen for aesthetic consistency. However, the underlying density of the tube was calculated using the weighted average of all lane widths in the city, which gives it the same density as the corresponding parking space bar, making these two bars directly comparable through their heights.

In the case of rails and bikes, a lane is encoded with the "way" data structure of OSM. Ways are polygonal chains, which makes rail and bicycle lanes homeomorphic to their coiled counterparts. In other words, they can be bent smoothly without the need for cuts or stitches. Car lanes, on the other hand, were defined by street name to be searchable. Streets are typically not simple polygonal chains, but multiple polygonal chains stitched together, representing trees or even more complex graphs that contain cycles. For example, Figure 2 shows a street with branches. Furthermore, usually there are multiple streets in a city with the same name. Therefore, to handle the coiling of streets, the platform was equipped with an algorithm for the noncontinuous transformation of each street graph into a chain of polygonal chains that can be bent smoothly. The algorithm iterates through all connected components; each component is traversed via Depth First Search. This step is repeated until no piece is left, taking care to store a minimal data structure during traversal which allows correct reconstruction of all pieces.

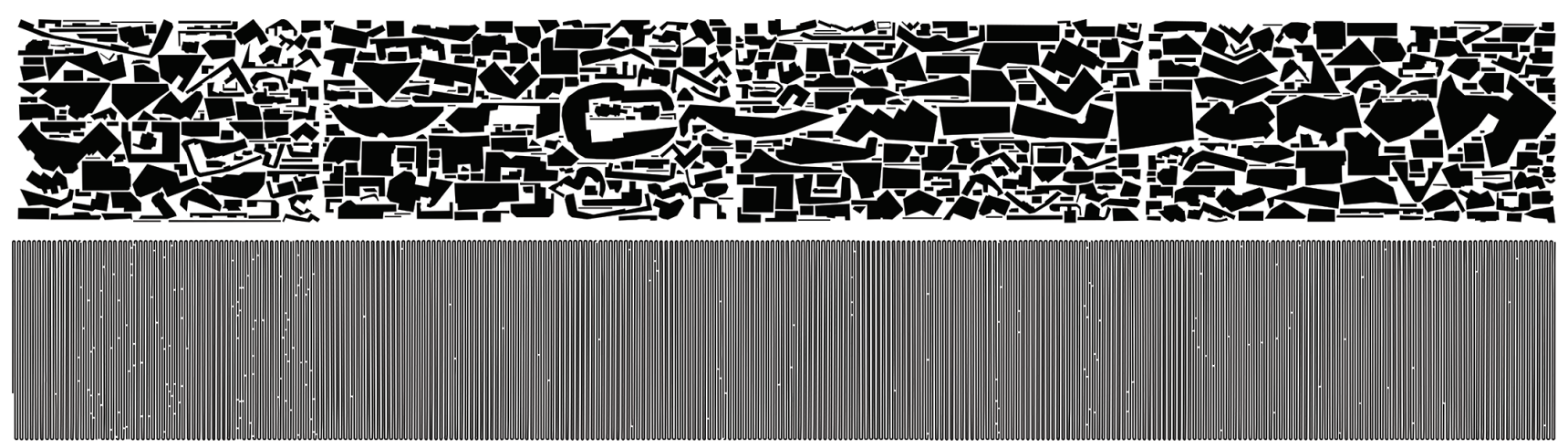

Figure 1. Top: All OSM car parking spaces of Johannesburg packed into a rectangle using the polygon packing library SVGNest. Bottom: The matching area of a segment of coiled up OSM streets of Johannesburg. The figure is rotated by 90 degrees.

\footnotetext{
${ }^{4}$ http://svgnest.com
} 

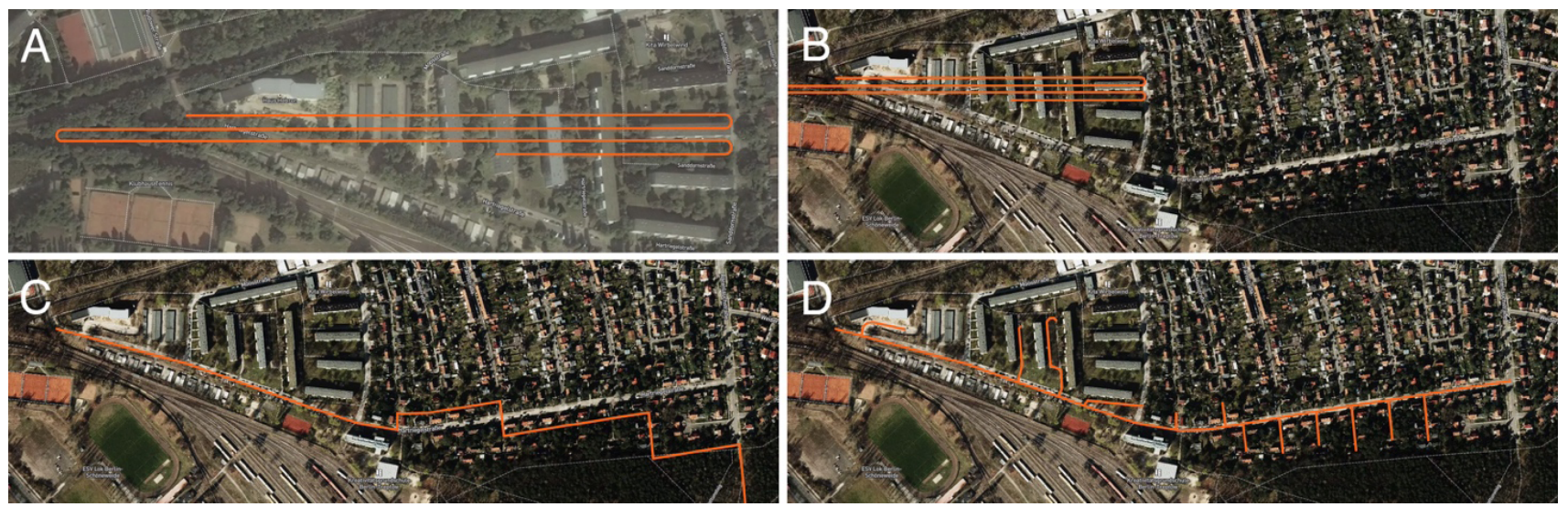

Figure 2. How a street uncoils: a. coiled view on map; b. zoomed out; c. unrolled; $d$. split up and translation of misplaced parts that previously exceeded the viewport in the bottom right corner-this is the original shape of the street.

\subsection{Individual Exploration and Animation}

As an additional way to engage visitors, all packed and coiled objects are interactive and individually explorable. Figure 3 illustrates the main interface, with car parking spaces packed on the left bar and streets coiled on the right. Information is given on the top center on the total amount of so far scrolled area, here $419,489 \mathrm{~m}^{2}$, in a human readable way, of 2.2 Boston Common landmarks. An individual landmark was selected for each city, e.g. Central Park in New York City or Hyde Park in London. Scrolling along the bars highlights individual elements on each bar, providing additional information: neighborhood (East Boston), street name (Appleton Street), and area. When clicking on a parking space, the polygon appears on a map and rotates from the packed minimumwidth orientation into its correct map orientation, dis- playing information on how many cars or bikes can be accommodated approximately. When clicking on a lane, the coiled lane appears on the map and uncoils into its original position on the map (Figure 2), displaying information on length and area of the lane. If the street is not made up of a single polygonal chain, only one component is now in place, while all other components are attached to one end being misplaced (Figure 2c). In this case, a second step in the animation translates the misplaced pieces, ensuring that all pieces of the street return to their original place on the map (Figure $2 \mathrm{~d}$ ).

\section{Visual Assessment of Space Imbalance Using the Mobility Triangle}

Parking spaces are packed and lane spaces are rolled into bars that can be compared to each other by scrolling
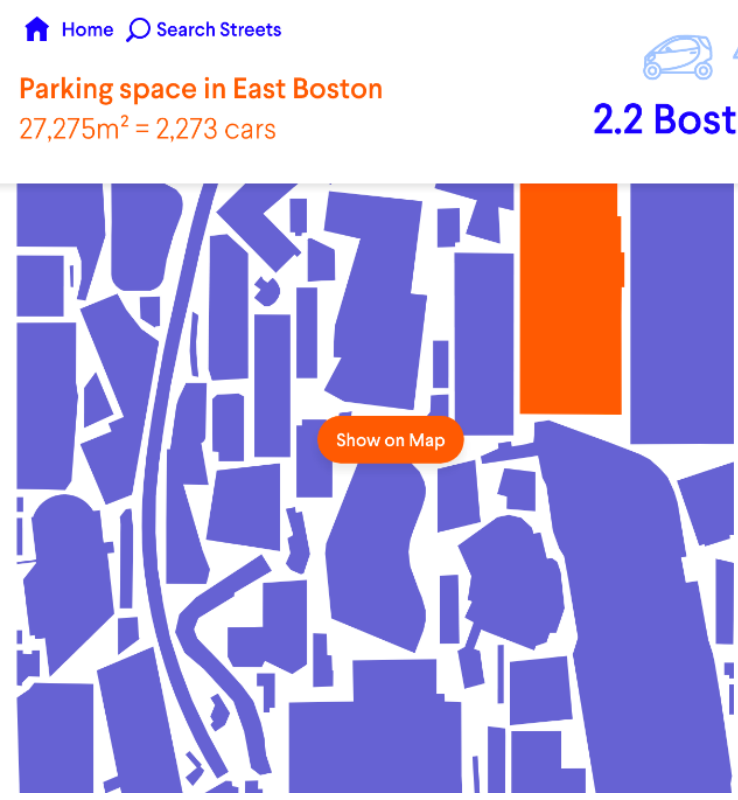

$419,489 \mathrm{~m}^{2}$

2.2 Boston Common

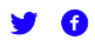

Appleton Street $634 \mathrm{~m}=5,040 \mathrm{~m}^{2}$
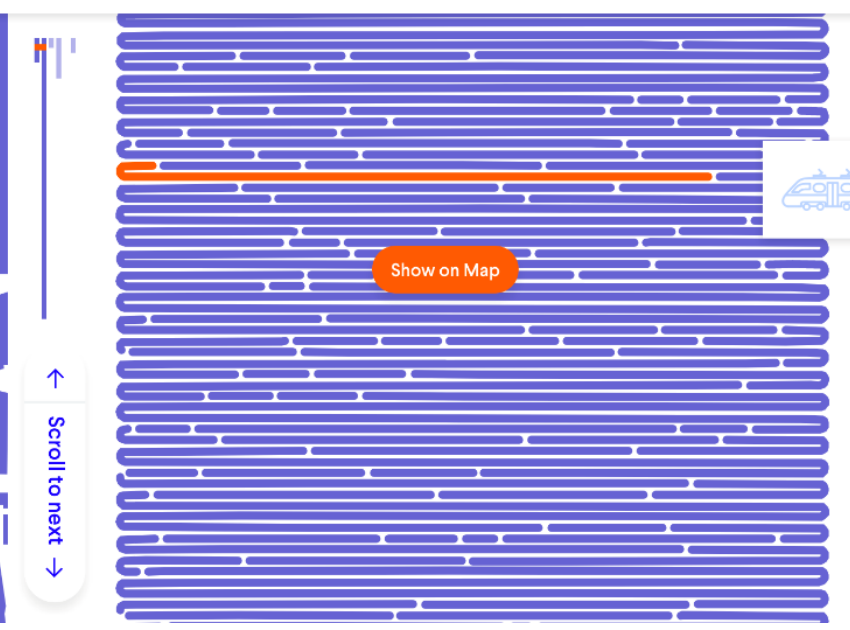

Figure 3. The main interface allows scrolling through all mobility spaces, here shown for cars in the city of Boston: on the left a segment of the bar of packed parking spaces, on the right the coiled streets with all individual elements explorable in detail (one on each side highlighted in orange). 
through them. The time needed to scroll through the vast car spaces, in contrast to the rather short bike spaces, gives an intuitive, dynamic perception of their inequality. However, there is a more compressed form of comparing these spaces to each other that does not require scrolling or comparing bar heights.

Each city has its own distribution of total car to rail to bicycle space, given by a triple $(X, Y, Z)$ where $X+Y+Z=1$. These variables identify the Cartesian coordinate $(x, y)$ with $y=Y^{*} \sin (\pi / 3)$ and $x=X+y^{*} \cot (\pi / 3)$, encoding the distribution as a single point in a ternary plot (Figure 4). A dot in the top corner of this triangle means all mobility spaces are car spaces, a dot in the bottom left corner means they are all rail spaces, and a dot in the bottom right corner means they are all bicycle spaces. A dot in the center of the triangle means that an equal share of space is allocated to each of these three forms of transportation.

The same coordinate transformation can be performed for the city's modal share, yielding a second data point. Connecting both dots in the ternary plot yields the "mobility triangle". It shows with just two data points the discrepancy between allocated space distribution and how people actually move. If first and second dots coincided, it would mean that city space is allocated in a fair way towards all forms of mobility: cars, rails, and bicycles receive the same fraction of space that they "deserve" from their usage. To give some real-world examples, Figure 4 shows the mobility triangle for the cities of Bei- jing, Berlin, Budapest, Copenhagen, Los Angeles, Rome, and Tokyo. Apparently, the dots representing allocation of space are clustered toward the top car corner of the triangle, while the modal share dots are spread towards the bottom and to the right, visualizing how many more people use other forms of mobility than is allocated for cars. We chose these specific 7 cities out of the 23 available ones ${ }^{5}$ for Figure 4 because of the visual separation of their data points, and because they cover the most extreme cases (modal share dominated by rails, bicycles, or cars).

For comparison, we present the same data in the form of a table (Table 1). The stark contrast in accessibility highlights why visual communication is far superior for numerical data, an insight established since at least the 19th century:

The graphical method has considerable superiority for the exposition of statistical facts over the tabular. A heavy bank of figures is grievously wearisome to the eye, and the popular mind is incapable of drawing any useful lessons from it as of extracting sunbeams from cucumbers. (Farquhar \& Farquhar in Wainer, 2005, p. 9)

\section{Empirical Evaluation of Space Inequality Perception}

Before engaging platform visitors into any of the above interactive visualizations, the platform invites them on its

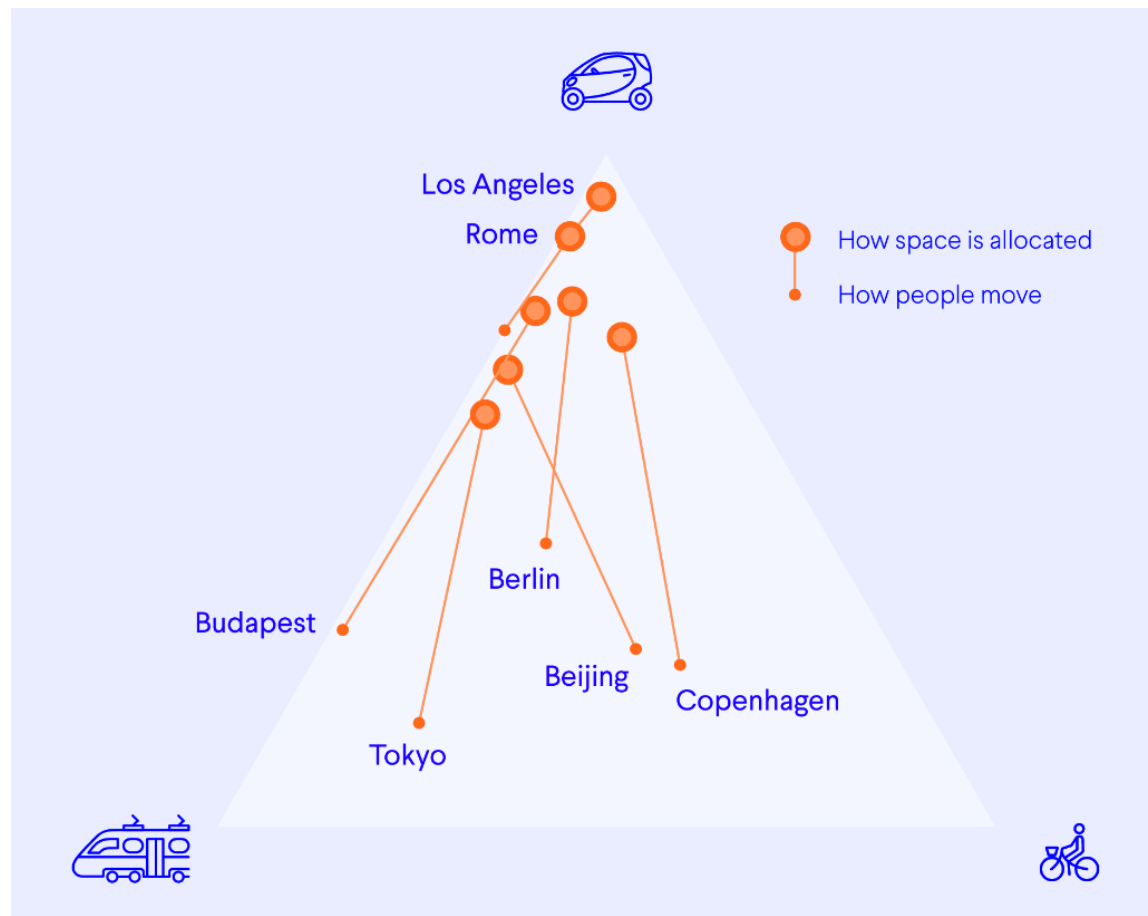

Figure 4. The mobility triangle expresses visually the discrepancy between mobility space distribution ("How space is allocated") and modal share ("How people move") as a connected pair of dots in a ternary plot, shown for seven selected cities.

\footnotetext{
${ }^{5}$ The mobility triangle is shown online for all 23 cities on the platform page, though with higher visual clutter. To avoid such visual clutter we recommend to limit the number of cities displayed in the same mobility triangle plot to not more than 8 .
} 
Table 1. Mobility space distribution versus modal share in seven selected cities. Modal shares do not sum up to 100 because of walking which accounts for the remainder. Some space distribution rows do not sum up to 100 due to rounding.

\begin{tabular}{|c|c|c|c|c|c|c|}
\hline \multirow[b]{2}{*}{ City } & \multicolumn{3}{|c|}{ Space Distribution (\%) } & \multicolumn{3}{|c|}{ Modal Share (\%) } \\
\hline & Automobile & Rail & Bicycle & Automobile & Rail & Bicycle \\
\hline Beijing & 68 & 29 & 3 & 21 & 26 & 32 \\
\hline Berlin & 78 & 15 & 7 & 30 & 26 & 15 \\
\hline Budapest & 77 & 21 & 3 & 20 & 47 & 1 \\
\hline Copenhagen & 73 & 12 & 16 & 23 & 27 & 45 \\
\hline Los Angeles & 92 & 4 & 4 & 78 & 11 & 1 \\
\hline Rome & 88 & 11 & 1 & 68 & 24 & 0 \\
\hline Tokyo & 61 & 35 & 4 & 12 & 51 & 14 \\
\hline
\end{tabular}

landing page to make a guess, asking for their estimate on how much space is allocated to the different forms of mobility. This invitation is formulated via two questions: "Who owns cityname?" (Figure 5), and "City space is limited! What do you think, how much space is allocated to the different ways of moving through the city?", where cityname stands for the name of one of the currently 23 covered cities, ${ }^{6}$ and is automatically pre-selected to be closest to the visitor's location, estimated by IP address. The guess is made with a set of 3 sliders linking cars, rails, and bicycles, adding up the percentages to $100 \%$. A guess is recorded only if the individual moves any of the linked sliders and makes her choice later than 8 seconds after having arrived on the page.

The platform collected 2,436 guesses from people across the 23 cities between the 4 th and 25th of July 2017; the results are reported in Figure 6. Box plots visualize the guesses versus dot markers that show space al- location as determined by the OSM data. The data show that people consistently overestimate the space given to bicycles, and underestimate the space given to cars. In 22 of the 23 cities, the median of guesses for bicycle space lies above the fraction as determined from the OSM data. The exception is Helsinki; however, here we suspect an issue with OSM data or the way the platform is parsing it, since an allocated bicycle area of $26 \%$, much more than the $16 \%$ in Copenhagen and 19\% in Amsterdam, seems unrealistic. We measure a similar, but inverted picture for the perception of car space. In 22 of the 23 cities, the median of guesses for car space lies below the fraction as determined from the OSM data. The only exception is Vienna, where the median of guesses is $67.5 \%$, slightly above the OSM fraction of $63 \%$.

There are possible biases which call for a careful interpretation of the significance of these results. First, it is not clear how the initial configuration of the slid-

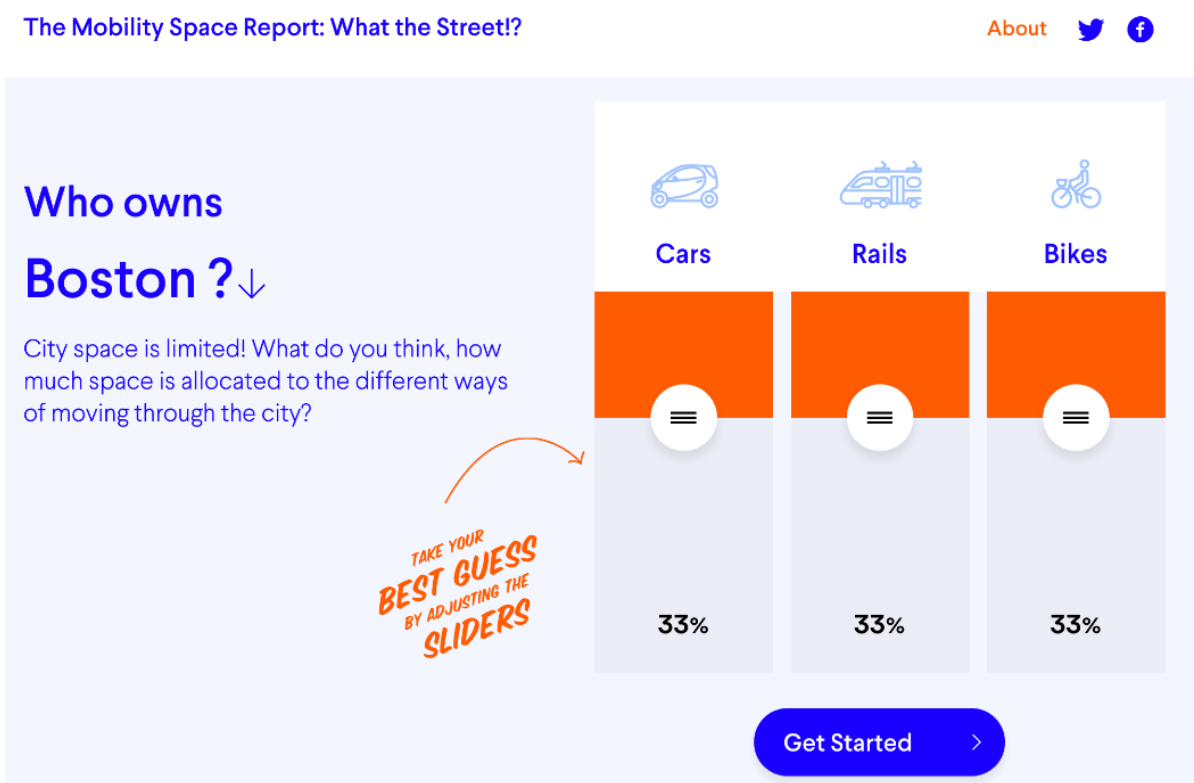

Figure 5. Using a linked set of sliders, empirical guesses on the distribution of mobility space are collected on the landing screen from site visitors.

\footnotetext{
${ }^{6}$ Amsterdam, Barcelona, Beijing, Berlin, Boston, Budapest, Chicago, Copenhagen, Helsinki, Hong Kong, Jakarta, Johannesburg, London, Los Angeles, Moscow, New York City, Portland, Rome, San Francisco, Singapore, Stuttgart, Tokyo, Vienna.
} 

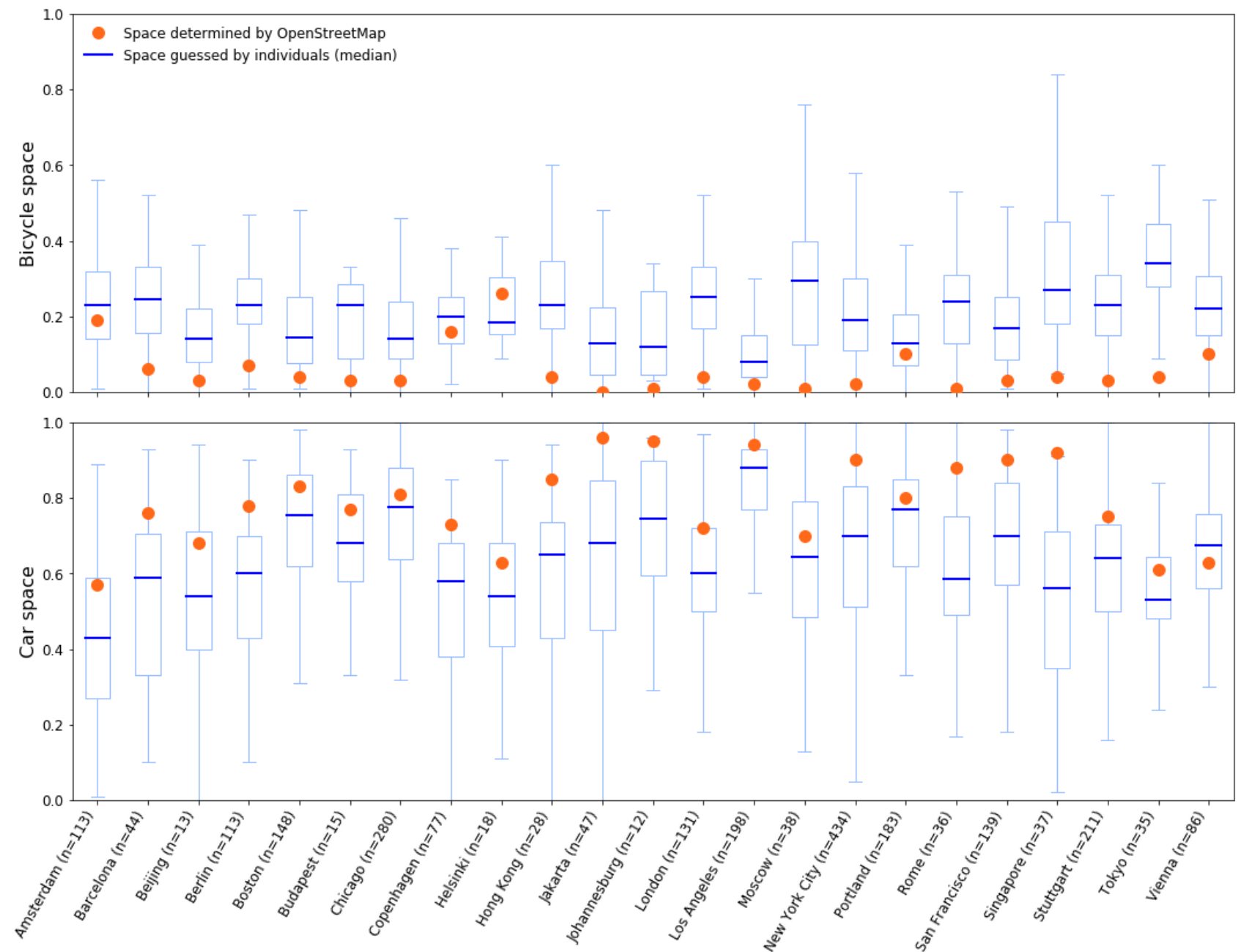

Figure 6. Guesses collected show that people consistently overestimate the space allocated for bicycles (top) and underestimate the space allocated for cars (bottom).

ers at $33 \%-33 \%-33 \%$ or the order "Cars-Rails-Bikes", Figure 5 , biases the guesses. It is possible that this setup shifts choices towards a more homogeneous distribution due to anchoring bias. There is survey-methodological research on slider bias versus radio button bias (Couper, Tourangeau, Conrad, \& Singer, 2006), however with unclear relevance since the platform uses linked sliders. We are not aware of survey bias research on the rarely used linked sliders. Second, it is not clear how the loaded question "Who owns cityname?" biases guesses. Third, most of the individuals who arrived at the platform were referred to from media sites that covered the spatial inequality aspect, mostly in English or in German. The individuals in this biased sample are therefore likely already sensitive to transport injustice and should tend towards a more informed guess than average internet users. Fourth, on top of this sample bias, it can also be inferred that most of the site visitors are WEIRD (Western, educated, and from industrial, rich, democratic countries) because of the number of guesses being heavily skewed towards Western locations: $n>100$ guesses are made for each US city and for several European cities, but there are only $n \ll 100$ guesses for the other cities. (All sample sizes are shown in brackets in Figure 6.) We do not know how many of the site visitors are locals, i.e. living in the city about which they make their guess, or if they make guesses only in their IP-assigned or in multiple cities, but we assume that whenever they make one or more guesses then at least one of these is in their assigned city. The differences in guesses between different cities suggests that a substantial fraction of the individuals is not guessing independently of the city, but consists of either locals or is sensitive towards differences in space allocation. For example, Los Angeles, a wellknown sprawl city, has a median guessed car space of $88 \%$ ( $\pm 14 \%$ SD), while this guess is less than half, $43 \%$ $( \pm 21 \% \mathrm{SD})$, for Amsterdam which is known for its bicycle culture. The correlation of guessed medians versus OSM areas over all cities is $\rho=0.63(p=0.0013)$ for cars. Interestingly there is no significant correlation for bicycle spaces, $\rho=0.04(p=0.84)$, suggesting that most individuals judge a city by its car space (which might be influenced by the slider order "Cars-Rails-Bikes"). The strong correlation for cars shows that people consistently underestimate car space even though they adjust their guesses towards the real situation. 
To sum up, there are possible biases that could have skewed the results in both directions, and the differences between guesses and space allocations are not statistically significant for any single city, in terms of mean \pm 2 SD, due to the high variation of guesses. However, the consistent underestimations of car spaces across the board means that the overall result is significant: the probability for the null hypothesis of underestimating $22 / 23$ cases by random chance is $23^{*} 0.5^{23}<0.001 \%$. Therefore, we interpret our empirical observations as adequate evidence that the issue of unequal space allocation between modes of mobility is underestimated by most people. This result makes the issue of urban transport injustice even more pressing, as car space is underestimated by the general public. (Further research is however needed to confirm this misperception and to understand how it effects urban planning processes and transport policy decisions either directly by biased decision makers or indirectly through a biased population that lacks motivation to assert political pressure towards sustainable transport solutions.)

\section{Exploring a Scenario on Parking Space Reduction}

The last section of the platform explores the scenario in which all privately owned cars are replaced by shared, self-driving vehicles. Due to much more efficient use of the vehicles, the fleet is assumed to be reduced by
90\% (OECD, 2015) with parking spaces reduced by $93 \%$ (Friedrich \& Hartl, 2016). For each city, the platform gives key statistics and a graphical impression on total saved landmarks, from Vondelparks in Amsterdam to Schlosspark Schönbrunns in Vienna (Figure 7). Without information on on-street parking, the numbers shown only account for a city's registered vehicles and are thus vastly underestimating the total reduced parking area-for some US cities at least 3.3 to 7-fold (Chester et al., 2015; Shoup, 2005). Further underestimations come from differences in counting parking spaces. For example, Chester et al. (2015) find that area devoted to parking is actually 1.4 times larger than the total area of roads in Los Angeles county. This discrepancy comes from methodological differences: they count individual parking spaces, including multi-story parking garages, while the platform only considers surface area taken up by parking. The methodological underestimation of the platform, apart from data limitations, underlines the huge amount of space devoted to road infrastructure and difficulties in assessing the actual scale of it.

Although this particular scenario is based on simulations in optimal settings, without discussing feasibility nor possible unintended consequences, the visualization provides a proof of concept how crowdsourced online platforms could be useful for accessible urban scenario planning (Peterson, Cumming, \& Carpenter, 2003). Note that a more recent study using data-driven simulations in

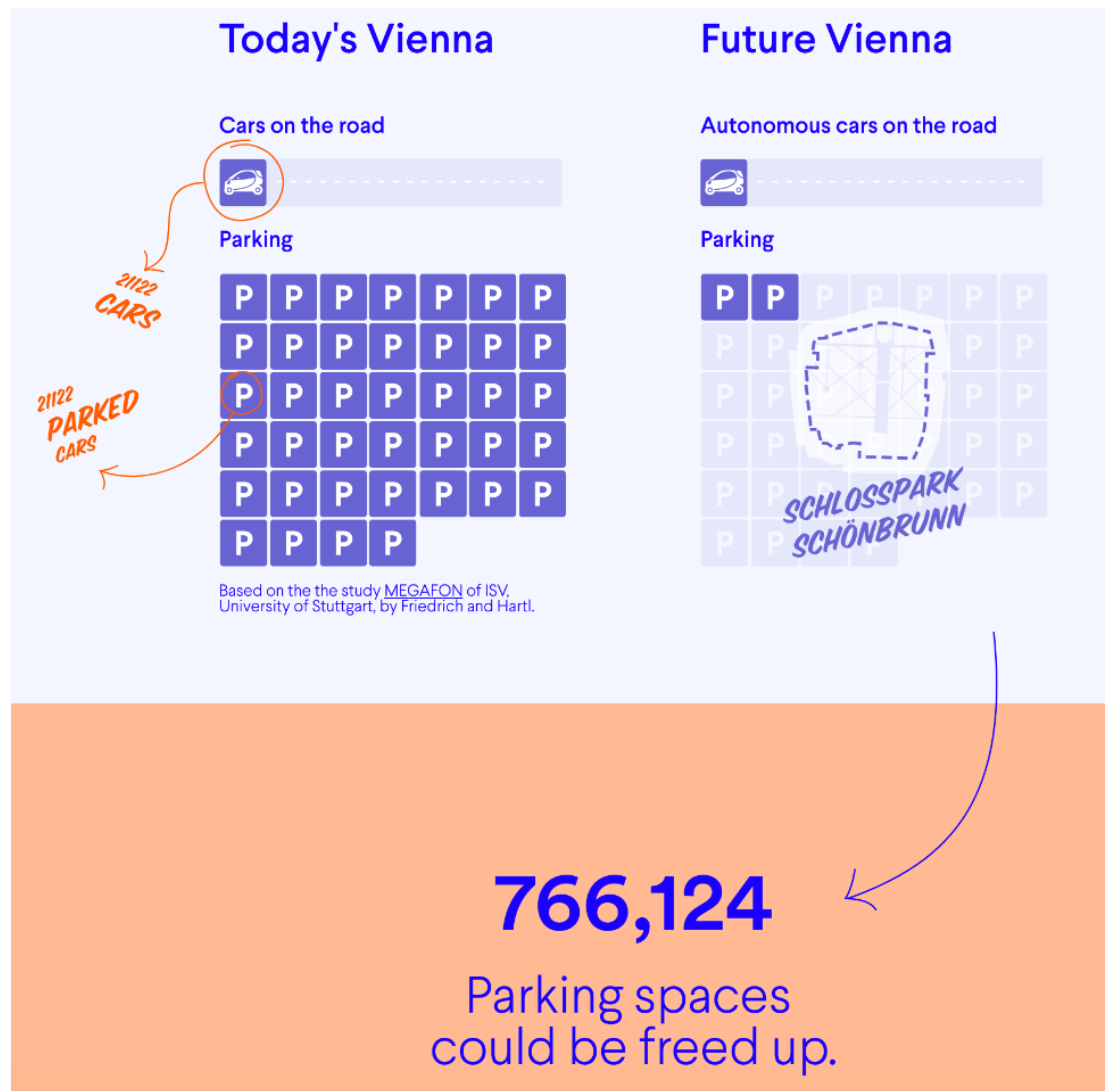

Figure 7. The spatial consequences of a scenario in which all cars in a city are replaced by an autonomous, shared fleet of vehicles. 
Singapore reports parking space reductions through selfdriving vehicles in the order of only $50 \%$, at the expense of increasing total traveled kilometers by less than $2 \%$ (Kondor, Zhang, Tachet, Santi, \& Ratti, 2017). As quantitative research on parking spaces is extremely sparse despite its fundamental role in city planning (Chester et al., 2015; Shoup, 2005) further research on the topic is urgently needed.

\section{Data and Design Limitations}

The biggest limitation of crowdsourced platforms is their data source, in this case OSM, and all the biases and shortcomings that these sources entail.

\subsection{Data Quality}

OSM is one of the largest examples of volunteered geographical information (VGI) today, having over 2.8 million registered users and over 3.4 billion contributed geographic data points (Zhang \& Malczewski, 2017). Although there are research gaps in defining appropriate quality indicators, the VGI data quality literature focuses on the following main measures: completeness, consistency, and positional accuracy (Senaratne, Mobasheri, Ali, Capineri, \& Haklay, 2017).

The main completeness issue of VGI systems such as OSM is the heterogeneity of users and records due to the digital divide. In particular, Haklay (2010) demonstrated the lack of coverage in non-Western parts of the world, and within each region in rural and poorer areas:

Places that are perceived as 'nice places', where members of the middle classes have the necessary educational attainment, disposable income for equipment, and availability of leisure time, will be covered. Places where population is scarce or deprived are, potentially, further marginalised by VGI exactly because of the cacophony created by places which are covered. (Haklay, 2010, p. 700)

This heterogeneity is also a major source of discrepancy between OSM and governmental bodies like the Ordnance Survey that operate on the principle of universal service. Haklay (2010) found, for example, a high variation in the coverage rate of English roads-between $46 \%$ for the poorest, and $76 \%$ for the wealthiest neighborhoods. Variations in completeness also stem from a heterogeneity of users. OSM contributions are made by both power users and occasional users, who produce no bias in terms of content, but a bias in meticulousness that varies from culture to culture (Quattrone, Capra, \& De Meo, 2015).

The issue of positional accuracy comes down to the same argument. Haklay, Basiouka, Antoniou, and Ather (2010) argue that Linus' law applies to accuracy in the case of OSM: "Given enough eyeballs, all bugs are shallow" (Raymond in Haklay et al., 2010, p. 70). Haklay et al.
(2010) demonstrate in a quantitative example an inverse, nonlinear relationship between the number of contributors and average positional accuracy of the English road network: 15 or more contributors can improve accuracy to below $6 \mathrm{~m}$ from a single-contributor accuracy of $11 \mathrm{~m}$. Comparison between the OSM and the ordnance data shows a quite accurate $80 \%$ overlap of motorway objects between the two datasets. However, this result refers only to covered areas, and again the problem of completeness dominates. Because of this and further issues, Zhang and Malczewski (2017) conclude that Linus' law is not applicable in VGI in general.

Given these issues, any rigorous assessment of mobility spaces, as collected from OSM by a visualization platform has to proceed with utmost caution. Absolute areas are most certainly not comparable between different cities. For example, Jakarta has an area of $661.5 \mathrm{~km}^{2}$, and in OSM a total car parking area of $1.37 \mathrm{~km}^{2}$. On the other hand, Singapore, covering a similar landmass of $719.1 \mathrm{~km}^{2}$, has an OSM total of $4.23 \mathrm{~km}^{2}$ car parking space. It is not clear whether this 3-fold discrepancy is rooted in a lack of OSM users in Jakarta, in the way OSM users record data, or in actual differences-OSM data of Singapore contains a few extended parking spaces and a large number of small-sized ones, while Jakarta does not contain many small spaces.

If absolute areas are not comparable globally, how can crowdsourced geographical information be useful to assess mobility space inequality? We argue that, despite the absolute differences between different cities, the relative differences within a city should be more stable. Apart from possible cultural biases (Quattrone et al., 2015), it seems reasonable to assume no significant difference in the biases in which the areas of car space, bicycle space, or rail space are recorded by users within the same city. Given this assumption, the central limit theorem implies that with enough spaces sampled from these three sources, the collected sample distribution converges towards the distribution of all spaces, meaning that the car to bicycle to rail areas sampled by OSM will closely resemble the true distribution. However, further research is required to assess the influence of user heterogeneity and how VGI co-evolves with modal share and urban space.

\subsection{Missing On-Street Parking by Design}

OSM does not record on-street parking in a polygonal format, but rather includes on-street parking information using parking:lane attributes within highway features. Because of this limitation, the area and shape of on-street parking is not available by design. In fact, cities themselves often do not have an up-to-date inventory of their parking spaces, and researchers are dependent on manual sampling methods. Following such an approach, Weinberger, Seaman, Johnson and Kaehny (2008) have shown that on-street parking can be a considerable fraction of all parking in a city. Therefore, by only considering 
off-street parking through the amenity=parking tags, an OSM based tool is likely vastly under-estimating the total car parking area within a city. In case that an OSM street contains a width attribute, it is not clear whether the user who added the tag intended to include on-street parking space; however, we assume this not to be the case because OSM specifies on-street parking information to be dealt via the parking:lane attribute. In case of no width attribute, the platform uses lane information and approximate fallback values for default street widths that do not contain on-street parking.

\subsection{Missing Pedestrian Spaces}

Although OSM has a sidewalk attribute it seems to be rarely used. Because of this lack of data, the area and shape of pedestrian mobility spaces is not available, apart from explicit off-street footpaths. Further, footpaths have no parking equivalent like the other forms of transportation, so the design of the platform would break. However, adding pedestrian spaces through other data sources (see Section 7), would be desirable to understand how motor-dependent or how walkable a city is.

\subsection{Overlaps in Mobility Space}

Different modes of transport often use overlapping spaces. For example, buses usually use the same road space as cars, bicycles use road space when there are no protected bicycle lanes, or tram rails might overlap with car space. Therefore, a unique attribution of each square meter of mobility space to one form of transportation is not possible. We followed a few simplifying steps that might distort the space inequality assessment. First, bus space was entirely ignored due to the substantial overlap with car space, and because it is not straightforward to quantify these spaces from the OSM data. Instead of a distinction into cars, public transport, and bicycles, space was split into cars, rails, and bicycles. Second, bicycle space was not considered whenever it neglected established practices of physical separation from car traffic as encoded by the cycleway=lane tag. Only physically separated bicycle space was considered, using the tags highway=cycleway, bicycle=designated, and cycleway=track (see Section 6.5). Third, possible overlaps of rail with car spaces were ignored. It could be argued that rail infrastructure competes less for mobility space than overlapping spaces do such as car and bicycle spaces. A possible alternative version of the mobility triangle could therefore replace rail space with pedestrian space.

\subsection{Protected versus Unprotected Bicycle Space}

The platform only considers protected bicycle lanes, i.e. lanes that are physically separated from vehicular traffic. Although it is outside the scope of this article to analyze bicycle infrastructure and cyclist injury rates, this choice is important and deserves an explanation. We first re- fer to the literature on bicycle infrastructure safety to argue why this is a reasonable choice, and then show that even if the platform were to consider both protected and unprotected bicycle lanes, it would not make a relevant difference-both the mobility triangle and the results on infrastructure perception would stay qualitatively the same.

Researchers who study bicycle infrastructure and injuries report growing evidence on two necessary ingredients for making bicycle infrastructure safe: 1) physical separation from vehicular traffic, and 2) improved intersection design. For example, Teschke et al. (2012) study injury risk in Canadian cities using a case-crossover design for statistical control via within-route randomization, finding a 9 times lower injury prevalence on physically separated cycle tracks than on reference routes. Shared bicycle infrastructure shows no significant risk reduction. Reynolds, Harris, Teschke, Cripton and Winters (2009) review 23 papers on the topic and report that roundabouts in particular can pose an increased risk to cyclists if cycle tracks are not separated. Pucher and Buehler (2016) review 8 recent studies and conclude that decades of evidence in Europe and the US demonstrate clear evidence that it is "crucial to provide physical separation from fastmoving, high-volume motor vehicle traffic and better intersection design" (p. 2090). These insights are not only academic, but increasingly are incorporated into policy guidelines such as the National Association of City Transportation Officials (2017) guidelines, which now recommend protected bicycle lanes as best practice except for the special circumstance of streets with low-speed, lowvolume motor vehicle traffic. It therefore makes sense to not consider bicycle space that is accessible by cars, as it cannot be considered safe for cyclists in typical traffic conditions. Despite all the empirical evidence found so far in favor of protected bicycle lanes, cycle tracks are perceived less safe by the public than observed, while multiuse paths are perceived safer than observed (Winters et al., 2012). Further, since the OSM data do not allow to distinguish between properly and improperly designed intersections and lanes, the OSM protected bicycle lanes can only be considered a proxy for best practice implementations.

Because bicycle infrastructure safety literature is still sparse, let us ask: Are these results robust to the issue of protected versus unprotected bicycle lanes? To understand this question, we counted all unprotected bicycle ways via cycleway=lane OR cycleway=opposite_lane OR cycleway=share_busway from OSM and calculated how much their count increases from the previously considered count of protected bicycle lanes. We find that 12 of the 23 cities add only less than $10 \%$ bicycle ways if also unprotected ones are considered (Hong Kong $0 \%$, Helsinki $1 \%$, Singapore $1 \%$, Moscow $2 \%$, Tokyo $2 \%$, Rome $2 \%$, Amsterdam 3\%, Stuttgart 4\%, Jakarta 5\%, Beijing 6\%, Copenhagen 7\%, Barcelona $8 \%$ ). Seven cities add between $10 \%$ and $50 \%$ (Johannesburg 15\%, Portland 29\%, Berlin 33\%, London 35\%, Chicago 36\%, Bu- 
dapest $39 \%$, Vienna $42 \%$ ). The final four cities are all from the US: Boston 73\%, New York 160\%, Los Angeles $182 \%$, San Francisco $222 \%$. Since these cities have an already negligible absolute area of bicycle infrastructure, doubling or tripling it does not make any qualitative difference in the mobility triangle (Figure 4), nor in the result on misperception (Figure 6). In light of the previous discussion of how most unprotected bicycle lanes could be considered unsafe, it is not surprising that the Western country with the strongest car culture has by far the highest ratio of unprotected bicycle space. This preliminary observation motivates further research on whether, how, or why societies that provide the least space for bicycles are also the societies that provide the most inadequate space for bicycles.

\subsection{Overlaps in Modal Share}

Modal share is the percentage of travelers commuting by walking, cycling, public transport, or private motor vehicle. There is an issue with this distinction in the context of the platform. As above, public transport incorporates buses, which share the same space as cars and cannot be uniquely separated. Further, public transport is a mix of bus and rail transport, which cannot be directly compared to the mobility space of rails because of the missing bus spaces. Therefore, a one-to-one mapping between mobility space and modal share is not possible, and the "How people move" dot in the mobility triangle (Figure 4) should be closer to the top corner if bus space is taken as car space. A general issue with modal share is its measurement via surveys by local governments without standardized methods, implying that modal shares of different cities have to be compared with caution. Here, the platform developers gathered modal shares from various official sources. ${ }^{7}$ Regardless of the data source, the contribution of the platform lies in a new visualization tool, in particular the mobility triangle. The accuracy of this visualization can only be as good as the accuracy of the underlying data.

\subsection{Web Design Limitations and Possibilities for Improvements}

The platform was developed by a team of 15 people in total, coordinated by moovel Group $\mathrm{GmbH}$, consisting of user experience designers, graphic designers, web designers, Javascript experts, mobility experts, and data scientists. This team had to balance web design, user experience, available web technology, and data limitations. For example, questions like "How many parking spaces can we fit into a browser window?" or "How do we load thousands of polygons into the browser and still make it scrollable smoothly?" had to be solved together. Because of many such constraints, the complexity of interactive parts, and a finite budget, there are still several possible avenues to improve the platform. For example,

\footnotetext{
$\overline{7}$ For a list of sources see https://en.wikipedia.org/wiki/Modal_share
}

it could be optimized for mobile view, a scale or landmark could already be shown during the 2-column view, there could be a tutorial, the types of roads or rail tracks could be distinguished, cars and busses could be merged as a "motor" category, or many usability improvements could be implemented such as accent-insensitive search ("Nador utca" should return the same street as "Nádor utca"). Fortunately, because the platform is opensourced, anybody is free to open an issue or to implement such improvements.

\section{Potential Use in Urban Planning and Outlook}

In the current form, the platform collects, quantifies, makes explorable, and summarizes with visual elements and key statistics the crowdsourced, massive data sets composed of millions of single mobility spaces from OSM spanning city limits. Primarily, it is useful as an educational tool for the public, to engage with the issues of sustainable transport and transport justice, and to make tangible how much parking space is wasted that could be utilized more meaningfully, through non-technical advances (policy changes) or technical advances (e.g. shared, autonomous cars). Such public engagement has the potential to improve public opinion and the measured misperception of sustainable transport and could indirectly back urban policy makers to reclaim road and parking space for pushing forward sustainable transport solutions (Chester et al., 2015). A public ranking of different cities could also come with positive competitive effects.

As a direct aid for urban planners, the platform gives a quantified overview of mobility space distributions spanning an entire city. Although inventoried data of such spaces may already be available to city administrations, the automatized merging and public processing provides a boost in accessibility. Because it is opensourced with an MIT license, it can be applied to any city, and extended or adjusted to fit particular use cases as a visual quantification software. For example, longitudinal data could be collected to compare developments in time, to check if new policies are required or have an impact, or to identify underdeveloped neighborhoods in need of focused investments.

\subsection{Longitudinal Extension to Study Induced/Disappearing Traffic}

The discrepancy between modal share and available space should not be underestimated, but cast in a systems dynamics perspective. The ternary nature of the mobility triangle is a hint at an evolutionary game theory setting where three strategies are competing against each other: extend infrastructure for car, extend infrastructure for rails, or extend infrastructure for bicycles. The urban planner's mix of strategies (choice of investments into different modes) drives the direction of the 
space allocation dot, which in turn influences the modal share dot due to induced traffic: investment into highways means increased supply of road space, which induces a higher modal share for cars, while investment into protected bicycle lanes increases sustainable bicycle traffic. Similarly, "road diets" and reducing free parking can cause disappearing traffic (Shoup, 2005; Speck, 2013; Weinberger et al., 2008). The impact and effectiveness of such policies could be analyzed visually in a longitudinal, possibly animated, extension of the mobility triangle. The examples of Figure 4 hint towards a non-linear relationship: in the cities of Los Angeles and Rome, where almost all space is allocated to cars, most people are forced to use them, and the discrepancy between space and modal share (the distance between the two dots) is small. In other cities, however, where there is slightly more space for rails or bicycles, like Budapest or Copenhagen, the corresponding forms of transport are much more widely used, leading to a clearly larger discrepancy. This discrepancy suggests that already a small change in infrastructure can provide large positive effects and return on investment-especially considering how inexpensive it is to build bicycle infrastructure.

\subsection{Extension of Spatial Scales}

A straightforward extension of the platform would be towards different spatial scales, and would give urban planners more options to explore space inequality and transport policies in neighborhoods, districts, areas of interest, agglomerations, or even whole countries. A freely selectable or importable bounding polygon would make the process maximally flexible.

\subsection{Scenario Planning for Performance Targets and Estimating Impacts}

For the purpose of urban planning, the most hands-on extension would be a feature for scenario planning (Peterson et al., 2003). Scenarios would allow urban planners to play through different transformations, to understand the potential impact of new space-related policies and how concrete performance targets can be reached. For example, many cities struggle with inadequate housing. A scenario planning tool could allow urban planners to understand what happens if a percentage of parking areas were turned into housing. It also could help to answer several questions: How would the narrowing of roads, the addition of protected cycling lanes, or the transformation of city centers into pedestrian zones, change traffic, pollution, walkability, or livability? What percentage of space would need to be converted, and how much investment would that take, to turn a city into the spatial equivalent of Copenhagen? How much sprawl is there (Gervasoni, Bosch, Fenet, \& Sturm, 2017)? All the established urban planning goals and indicators could be incorporated, such as climate protection and pollution re-

\footnotetext{
$\overline{8}$ http://opendata.cityofnewyork.us
}

duction, adequate and equitable access to housing and transport, health and safety measures like Vision Zero to reduce fatalities from collisions or the increase of daily walking time, open space and agricultural preservation, economic vitality, or transportation system effectiveness.

\subsection{Extended Crowdsourced Data Sets}

A platform like the one developed is not limited to transport spaces but could become a general visual framework for any kind of urban space inventory where objects are encoded as polygons, collections of line segments, or nodes. For example, the selection of spaces could be extended to amenities, buildings, land use (Fonte et al., 2017), natural areas, waterways, or any of the other built or natural spatial map features of OSM. However, special care has to be taken to fit, and possibly cut, too large elements such as forests, and to determine spatial extensions in case of zero- or one-dimensional map elements. With cutting edge open-source software packages like OSMnx, of which the platform is also making use, downloading, analyzing and visualizing open VGI has become an easy task (Boeing, 2017).

For the purpose of parking and walking space assessment, a desirable data extension would be on-street parking, sidewalks, and other pedestrian spaces. This data could come from VGI systems other than OSM, from commercial platforms, or from city space inventories. The problem with commercial platforms and official city inventories is that data is typically not accessible to the public. More efforts should be invested into establishing transparency laws and open data initiatives like the New York City OpenData project. $^{8}$ Extending crowdsourced data with data collected by governmental bodies would have the beneficial side-effect of decreasing data completeness biases. If no up to date information is available, parking data can also be complemented via growth simulations (Chester et al., 2015).

Implementing urban policies should not only follow objective goals, but should first and foremost be satisfactory for the citizens who live in the city. To balance public and private interests, it is therefore important to measure citizen requests and human perceptions of urban spaces. On the one hand, requests can be measured directly through interview surveys, such as in a recent study conducted in Germany by Gesellschaft für Konsumforschung (2017) which showed that $87 \%$ of citizens want more space for pedestrian and bicycle traffic. On the other hand, large-scale measurement processes can be designed efficiently by crowdsourcing (Quercia, O'Hare, \& Cramer, 2014; Salesses, Schechtner, \& Hidalgo, 2013) or by extraction from user-generated social media, allowing for 'obtain[ing] citizens' direct feedback for urban planning and as a supplementary decision support tool for ongoing planning processes using contextual emotion information" (Resch, Summa, Zeile, \& Strube, 2016, p. 124). 


\subsection{From Crowdsourced to Automatized Quantification}

While crowdsourced data always suffers from completeness biases, a potentially truly complete approach to assess urban space distribution could come through the recent revolution in automatized machine learning methods (LeCun, Bengio, \& Hinton, 2015). In particular, visual methods like image recognition and computer vision have the potential to transform urban planning through the large-scale, automatized identification of urban patterns and dynamics using satellite (Albert, Kaur, \& Gonzalez, 2017) or street-level images (Naik, Kominers, Raskar, Glaeser, \& Hidalgo, 2017). Such automatized methods come with the need of human-level validation-crowdsourced or in the form of precise inspection (Gössling et al., 2016) — combining automatized with manual approaches. In the example of the platform, image recognition algorithms could identify and measure all different mobility spaces, including sidewalks and on-street parking spots, from satellite images instead of relying on biased user inputs.

\subsection{Beyond Space Equality}

When comparing allocation of urban mobility space in absolute values, cars naturally take away more space than any other forms due to the high per person area, as discussed in Section 1.1. Therefore, the observed unequal distribution of allocated space is a consequence of both this inherent spatial imbalance and of policy decisions. Given this insight one might ask: Is our definition of equality unfair? Should we accommodate cars and correct for their inherent spatial requirements? If our aim is to measure absolute allocation of space or to raise public awareness of the issue, the answer should be a resounding "No" - the function of urban transport infrastructure is to move people, not arbitrarily large, mostly empty vehicles. However, it could make sense to extend the platform with a rescaling option to disentangle the contributions of inherent space and of policy decisions to understand if a city is favoring cars even above their inherent space requirements. On the other hand, treating cars at the same level as sustainable forms of transport creates a false equivalence and unreasonably accommodates car culture. Besides an array of problems (see Section 8) cars are infinitely more deadly than pedestrians or bicycles, in terms of pollution and as road hazard, and should therefore be reasonably discriminated against in any discussion of equality. Adding this correcting weight to space equality considerations would mean not only going from a) the status quo of prioritizing cars over sustainable mobility to b) a position where sustainable mobility is on an equal footing with cars, but to c) a prioritization of sustainable mobility over cars. Such reversal of prioritization could ultimately lead to a closer measure of fairness that accounts for human life and the way how citizens are treated, i.e. to optimize for livable cities through a human-centric concept of space equity.

\section{Further Issues with and Suggested Solutions for Car-centric Cities}

Beyond the spatial inefficiency of cars discussed in Section 1.1., there are a number of further sustainability issues, of which we highlight a few here. For a detailed discussion on the related three dimensions of transport injusticeexposure to traffic risks and pollutants, distribution of space, and the valuation of time-see Gössling (2016).

\subsection{Pollution}

Every year, ambient air pollution causes 3 million deaths worldwide (World Health Organization [WHO], 2017). The largest contributor to such pollutant-related mortalities is road transportation, dominated by cars, causing a large number of PM2.5-related deaths and ozone-related early deaths as an inherent by-product of combustion processes (Molina \& Molina, 2004; Caiazzo, Ashok, Waitz, Yim, \& Barrett, 2013). A further major problem of vehicular pollution is the rising concentration of greenhouse gases in the atmosphere, contributing to climate change (Moriarty \& Honnery, 2008).

For dealing with local health hazards, policy efforts such as a series of European Emission Standards are ongoing to reduce PM emissions of vehicle engines (Piock et al., 2011). Concerning greenhouse gases, a wide mix of technical solutions for improving fuel efficiency in cars has been developed and discussed, including alternative fuels, hydrogen fuel-celled vehicles or hybrid electric vehicles (Moriarty \& Honnery, 2008). While fuel efficiency has the potential to be improved by a factor of 4 over the following decades (Åkerman \& Höjer, 2006), Moriarty and Honnery (2013) argue that, despite such technical advances, an implementation of "green cars" is not a reasonable solution on a global scale, as several key variables cannot be assumed to be constant. For example, the observed growth of motorization and decrease of car occupancy rates will counteract all technical efforts spent on optimizing fuel efficiency-whether on the tank-to-wheel or well-to-tank level. Therefore, feasible solutions should be non-technical such as transport policy changes to reduce passenger travel levels (Moriarty \& Honnery, 2013). However, a recent example in China shows how massive government subsidies and non-monetary incentives can also provide a nontechnical solution to boost the explosive adoption of electric vehicles (Wang, Sperling, Tal, \& Fang, 2017). In any case, aggressive, visionary policymaking and considerable investments will be needed to achieve success (Fulton, Mason, \& Meroux, 2017). How frictionless such policies could be implemented in individualistic Western societies is an open question.

\subsection{Road Fatalities}

The ninth leading cause of death globally is road traffic crashes, causing 1.25 million people to die every year 
(WHO, 2015). Road fatalities are facilitated by a combination of poor safety regulations and inadequate road and vehicle standards, preferentially putting at risk the most vulnerable road users: motorcyclists, pedestrians, and cyclists (WHO, 2015). Recent social psychology research on driver attitudes analyzed the competition for mobility space from the perspective of social dominance theory, further showing that "drivers might view bicyclists as not just a momentary annoyance, but a threat to their social identity as a driver" (Goddard, 2017, p. 17), suggesting a "significant influence on bicycling uptake and bicyclist safety" (Goddard, 2017, p. 152) on top of the inherent physical risks.

In a future where all cars are fully autonomous, the yearly 1.25 million traffic fatalities could become a thing of the past, or could at least be severely reduced (Litman, 2017a). Although such hopes are mostly based on speculation, recent disengagement self-reports from autonomous car testing programs show a trend towards improved technological capabilities (Davies, 2017). However, the fundamental question is: How feasible is the diffusion of self-driving technology globally, and is that preferable to prioritizing infrastructure for the already proven, low-risk forms of mobility? Further, how is technology that was tested in ideal, Western conditions, performing in sub-optimal infrastructure and traffic conditions that exist in most parts of the world (WHO, 2015)? Answers to these questions are yet unclear.

\subsection{Lack of Health Benefits}

Vehicular mobility does not enjoy the extensive advantages of walking and in particular of cycling which includes fitness benefits and benefits in cardiovascular risk factors (Oja et al., 2011). As Gössling and Choi (2015) have demonstrated via cost-benefit analysis, this is also an economic argument: taking into account health benefits from cycling together with costs on climate change and road crashes, car driving is six times more costly to society (Euro 0.50/km) than cycling (Euro 0.08/ km). Although an extra health benefit should not have to be a requirement for designing transport infrastructure, making people sit less still during their travels can be an effective health intervention, especially relevant in today's global obesity epidemic (Frank, Andresen, \& Schmid, 2004). There is no obvious solution to the car's lack of health benefits.

\subsection{Usage Inefficiency: Sharing and Self-Driving Cars}

There are two main ingredients to how usage inefficiency (see Section 1.1) could be overcome. First, focus on increasing occupancy rates through sharing. Although formal ride sharing programs in the US have a long history of failure (Moriarty \& Honnery, 2008), strict high-occupancy policies in Jakarta have shown drastic improvements on city-wide traffic (Hanna, Kreindler, \& Olken, 2017), again demonstrating the power of non- technical solutions. Apart from such centralized policies, memberships in formal car and ride sharing programs are increasing in Western countries (Shaheen \& Cohen, 2007) and are becoming socially acceptable on a large scale through recent advances in information technology and the widespread use of smart phones (Ratti \& Biderman, 2017), coupled with changes in behavior that seeks access to mobility instead of ownership of a vehicle (Botsman \& Rogers, 2010). The boom of car sharing in the last decade shows that services like car2go, where one shared vehicle can replace up to 11 privately owned vehicles (Martin \& Shaheen, 2016), could replace a substantial part of current vehicles in the long run, significantly reducing the need for parking. On the level of taxis, ride sharing scenarios have already been implemented, and their potential benefits have been quantified rigorously-yielding substantial possible improvements in terms of reducing trips and pollution (Santi et al., 2014). Although in individualistic societies consistent success of ride sharing might be difficult to achieve due to locked in user expectations (Epprecht, Von Wirth, Stünzi, \& Blumer, 2014), Didi Chuxing self-reported massive savings in China in the order of 510 million liters of fuel over a year (World Economic Forum, 2016).

The second ingredient to better usage efficiency could come in the form of autonomous cars. If all existing vehicles were turned into a self-driving, public fleet, cars would not be bound to a specific human driver anymore, allowing to serve the emerging mobility needs of citizens on the fly, and to even complete freight transport during off-peak times. Combined with the possibility to share, simulated optimal scenarios suggest that the same vehicular mobility needs of today could be delivered with a $70 \%$ to $90 \%$ smaller fleet (OECD, 2015; Spieser et al., 2014). This more efficient use of cars could mean a reduction of massive amounts of parking space, up to $93 \%$ in the case of Stuttgart (Friedrich \& Hartl, 2016). At the same time, these scenarios also show that the overall volume of car travel would likely increase due to repositioning and service trips (OECD, 2015). Although public test drives of self-driving cars are being already deployed (Davies, 2017), the acceptance (Epprecht et al., 2014) and large-scale impact on society, with possible substitution and rebound effects, will likely not be clear until considerable numbers are tested in actual use (Ratti \& Biderman, 2017).

\subsection{No Solution for Spatial Inefficiency}

Unfortunately, there is no solution for the issue of spatial inefficiency, making the car the least sustainable form of transportation (Banister, 2005). Although spatial inefficiency might be reduced by sharing and more efficient space use on the road through reduced response times of autonomous vehicles by velocity matching, swarming (Ulbrich, Rotter, \& Rojas, 2016), and automatized intersection design (Ratti \& Biderman, 2017; Tachet et al., 2016), these efforts would be counteracted by the global 
increase in motorization, following the same arguments as above (Moriarty \& Honnery, 2013). At the same time, increasing the efficiency of cars induces traffic, further reinforcing rather than curbing unsustainable car-centric city planning (Fulton, Mason, \& Meroux, 2017). The sprawling space requirements of the car ultimately renders it inferior, even if implemented in the most efficient form, i.e. being environmentally-friendly, public, shared, and autonomous. Thus, for a sustainable urban future, it is paramount to focus on policy solutions and to prioritize the proven methods of mobility: walking, cycling, and mass transit. Such solutions, in particular those aimed at reclaiming space to make cities less car-dependent and more livable, include road diets, abolishing minimum parking requirements and free parking (Chester et al., 2015; Shoup, 2005), or localized car bans if feasible (Speck, 2013) that take into account behavioral responses to be effective (Guerra \& Millard-Ball, 2017). Although the high level of car use in cities today is uneconomic and unsustainable, limited numbers of cars might remain useful in special scenarios such as providing mobility for elderly or disabled people (Kamruzzaman, Yigitcanlar, Yang, \& Mohamed, 2016). In practice, pricing policies could be easily designed to correct the existing market distortions that currently over-subsidize cars, incorporating congestion, roadway costs, accident risk, parking, pollution, and fuel externalities, towards multimodal and socially optimal transport markets (Gössling, 2015; Litman, 2017b).

\section{Conclusion}

In this article we explored the spatial implications of almost a century of car-centric urban planning. In particular we focused on how to measure and visualize the inequality of urban mobility spaces on a large scale through crowdsourced data gathered via OSM. We described how the recently developed open-source online platform What the Street!? packs and coils all of a city's mobility spaces of cars, rails, and bicycles, and compares these spaces with each other and with their modal shares, making easily accessible the worldwide privileged allocation of urban space towards cars. The platform also highlights the massive spaces wasted through parking caused by inefficient use of cars. Finally, we analyzed guesses from site visitors, showing that this inequality of space is commonly underestimated. This biased perception of space possibly reinforces conservative, unsustainable transport planning. We showed how open volunteered geographic information enables public engagement with the issue of urban transport inequality, and how it could become a vital part of future planning tools, complementing traditional and automatic methods of urban land use assessment and transport planning.

We have added a spatial perspective to the mounting evidence that car-centric urban planning-which treats the city as a linear machine (Batty, 2013)-is one of the $20^{\text {th }}$ century's most impactful tragedies of the commons come true. It is responsible for a good part of the unfolding global catastrophe of climate change and has created cities with substandard living conditions stuck in gridlock. Initially being an issue of transport inequality that benefited the car industry and a privileged, vehicle-owning segment of the population at the expense of the poor, the paralysis of cities through the inefficiency of vehicular traffic has since long started to hurt all citizens alike. This outcome calls for the benefits of applying the scientific method on an all-encompassing basis instead of relying on myopic transport engineering (Speck, 2013) to make urban transport planning sustainable: 1) gather and analyze data, 2) understand which mix of mobility forms works best for the whole city in the long term, and 3) allocate space and develop infrastructure as needed. Most importantly, this process needs to be agnostic, i.e. without unreasonable prioritization of one form of mobility over others.

Although technical approaches like shared, selfdriving cars could free up massive parking spaces, they alone will not make urban transport sustainable. Such technical fixes bring at best temporary benefits, are infeasible to implement globally, and carry the danger of reinforcing the status quo of monocultural, car-centric urban planning and its negative consequences. With the majority of people now living in cities, along increasing worldwide urbanization and motorization, it is high time to reverse the systemic misdevelopments of $20^{\text {th }}$ century urban planning with bold policy making that implements sustainable, society-wide optimal, urban transport systems.

\section{Acknowledgments}

I thank moovel and the whole development team of What the Street!?, in particular Stephan Bogner, Benedikt Groß, and Thibault Durand, who were indispensable in the professional implementation of the visualization techniques. I am grateful for collaboration and fruitful discussions on the topic with the moovel lab team, especially with Raphael Reimann, Stephan Bogner, Benedikt Groß, Joey Lee, Tilman Häuser, and Eileen Mandir. I thank Raphael Reimann for providing the guess data set. I thank Thomas Rooney and Roberta Sinatra for helpful feedback on the manuscript, and Lara Szell for the encouragement. Figures 1-5 and 7 are derived from What the Street!? (c) moovel, MIT License.

\section{Conflict of Interests}

The author is a main developer of What the Street!? and was paid employee (researcher in residence) at moovel Group $\mathrm{GmbH}$, subsidiary of Daimler AG, during the creation of the platform. This research was conducted after What the Street!? had been implemented; the research and the decision to publish it was done independently of moovel Group GmbH or Daimler AG. 


\section{References}

Agentur für clevere Städte. (2014). Wem gehört die Stadt? Der Flächen-Gerechtigkeits-Report. Retrieved from https://www.clevere-staedte.de/files/tao/img/ blog-news/dokumente/2014-08-05_Flaechen-Gerech tigkeits-Report.pdf

Åkerman, J., \& Höjer, M. (2006). How much transport can the climate stand? Sweden on a sustainable path in 2050. Energy Policy, 34(14), 1944-1957. doi:10.1016/j.enpol.2005.02.009

Albert, A., Kaur, J., \& Gonzalez, M. (2017). Using convolutional networks and satellite imagery to identify patterns in urban environments at a large scale. arXiv preprint arXiv:1704.02965.

Banister, D. (2005). Unsustainable transport: City transport in the new century. Abingdon and New York: Routledge.

Bates, J., \& Leibling, D. (2012). Spaced out-Perspectives on parking policy. London: RAC Foundation. Retrieved from http://www.racfoundation.org/re search/mobility/spaced-out-perspectives-on-parking

Batty, M. (2013). The new science of cities. Cambridge, MA: MIT Press.

Boeing, G. (2017). OSMnx: New methods for acquiring, constructing, analyzing, and visualizing complex street networks. Computers, Environment and Urban Systems, 65, 126-139. doi:10.1016/ j.compenvurbsys.2017.05.004

Botsman, R., \& Rogers, R. (2010). What's mine is yours: The rise of collaborative consumption. New York: HarperCollins.

Caiazzo, F., Ashok, A., Waitz, I. A., Yim, S. H., \& Barrett, S. R. (2013). Air pollution and early deaths in the United States. Part I: Quantifying the impact of major sectors in 2005. Atmospheric Environment, 79, 198-208. doi:10.1016/j.atmosenv.2013.05.081

Chester, M., Fraser, A., Matute, J., Flower, C., \& Pendyala, R. (2015). Parking infrastructure: A constraint on or opportunity for urban redevelopment? A study of Los Angeles County parking supply and growth. Journal of the American Planning Association, 81(4), 268-286. doi:10.1080/01944363.2015.1092879

Colville-Andersen, M. (2013). The arrogance of space. The blog by Copenhagenize Design Co. Retrieved from http://www.copenhagenize.com/2013/03/thearrogance-of-space.html

Colville-Andersen, M. (2014). The arrogance of spaceParis, Calgary, Tokyo. The blog by Copenhagenize Design Co. Retrieved from http://www.copenhagenize. com/2014/09/the-arrogance-of-space-paris-calgary. html

Colville-Andersen, M. (2017). Arrogance of spaceCopenhagen-Hans Christian Andersen Boulevard. The blog by Copenhagenize Design Co. Retrieved from http://www.copenhagenize.com/2017/ 05/arrogance-of-space-copenhagen-hans.html

Couper, M. P., Tourangeau, R., Conrad, F. G., \& Singer,
E. (2006). Evaluating the effectiveness of visual analog scales: A web experiment. Social Science Computer Review, 24(2), 227-245. doi:10.1177/ 0894439305281503

Davies, A. (2017). The numbers don't lie: Self-driving cars are getting good. Wired. Retrieved from https:// www.wired.com/2017/02/california-dmv-autonom ous-car-disengagement/

Epprecht, N., Von Wirth, T., Stünzi, C., \& Blumer, Y. B. (2014). Anticipating transitions beyond the current mobility regimes: How acceptability matters. Futures, 60, 30-40. doi:10.1016/j.futures.2014.04.001

Fonte, C. C., Patriarca, J., Minghini, M., Antoniou, V., See, L., \& Brovelli, M. A. (2017). Using OpenStreetMap to create land use and land cover maps: Development of an application. In C. E. C. Campelo, M. Bertolotto, \& P. Corcoran (Eds.), Volunteered geographic information and the future of geospatial data (pp. 113-137). Hershey, PA: IGI Global.

Frank, L. D., Andresen, M. A., \& Schmid, T. L. (2004). Obesity relationships with community design, physical activity, and time spent in cars. American Journal of Preventive Medicine, 27(2), 87-96. doi:10.1016/ j.amepre.2004.04.011

Friedrich, M., \& Hartl, M. (2016). MEGAFONModellergebnisse geteilter autonomer Fahrzeugflotten des oeffentlichen Nahverkehrs. University of Stuttgart. Retrieved from http://www.isv.uni-stuttgart. de/vuv/news/Downloads/MEGAFON_Abschlussbe richt_V028_20161212.pdf

Fulton, L., Mason, J., \& Meroux, D. (2017). Three revolutions in urban transportation. Retrieved from https:// www.itdp.org/wp-content/uploads/2017/04/ITDP3R-Report-FINAL.pdf

Gervasoni, L., Bosch, M., Fenet, S., \& Sturm, P. (2017). Calculating spatial urban sprawl indices using open data. In 15th International Conference on Computers in Urban Planning and Urban Management. Adelaide, Australia.

Gesellschaft für Konsumforschung (2017). Platz für Begegnungen. Retrieved from https://www.adfc. de/presse/pressemitteilungen/gfk-umfrage-mehrplatz-fuer-begegnungen-weniger-fuer-autos

Glaeser, E. L., \& Kahn, M. E. (2004). Sprawl and urban growth. In J. V. Henderson \& J. F. Thisse (Eds.), Handbook of regional and urban economics (pp. 24812527). doi:10.1016/S1574-0080(04)80013-0

Goddard, T. B. (2017). Drivers' attitudes and behaviors toward bicyclists: Intermodal interactions and implications for road safety (Ph.D. dissertation), Transportation Research and Education Center, Portland, Oregon, USA.

Gössling, S. (2016). Urban transport justice. Journal of Transport Geography, 54, 1-9. doi:10.1016/ j.jtrangeo.2016.05.002

Gössling, S., \& Choi, A. S. (2015). Transport transitions in Copenhagen: Comparing the cost of cars and bicycles. Ecological Economics, 113, 106-113. 
doi:10.1016/j.ecolecon.2015.03.006

Gössling, S., Schröder, M., Späth, P., \& Freytag, T. (2016). Urban space distribution and sustainable transport. Transport Reviews, 36(5), 659-679. doi:10.1080/ 01441647.2016.1147101

Guerra, E., \& Millard-Ball, A. (2017). Getting around a license-plate ban: Behavioral responses to Mexico City's driving restriction. Transportation Research Part D: Transport and Environment, 55, 113-126. doi:10.1016/j.trd.2017.06.027

Haklay, M. (2010). How good is volunteered geographical information? A comparative study of OpenStreetMap and Ordnance Survey datasets. Environment and Planning B: Planning and Design, 37(4), 682-703. doi:10.1068/b35097

Haklay, M., Basiouka, S., Antoniou, V., \& Ather, A. (2010). How many volunteers does it take to map an area well? The validity of Linus' law to volunteered geographic information. The Cartographic Journal, 47(4), 315-322. doi:10.1179/ $000870410 \times 12911304958827$

Hanna, R., Kreindler, G., \& Olken, B. A. (2017). Citywide effects of high-occupancy vehicle restrictions: Evidence from "three-in-one" in Jakarta. Science, 357(6346), 89-93. doi:10.1126/science.aan2747

Hutton, B. (2013). Planning sustainable transport. Abingdon and New York: Routledge.

Kamruzzaman, M., Yigitcanlar, T., Yang, J., \& Mohamed, M. A. (2016). Measures of transport-related social exclusion: A critical review of the literature. Sustainability, 8(7), 696. doi:10.3390/su8070696

Kondor, D., Zhang, H., Tachet, R., Santi, P., \& Ratti, C. (2017). Estimating savings in parking demand using shared vehicles for home-work commuting. arXiv:1710.04983v2.

LeCun, Y., Bengio, Y., \& Hinton, G. (2015). Deep learning. Nature, 521(7553), 436-444. doi:10.1038/ nature14539

Litman, T. (2017a). Autonomous vehicle implementation predictions. Victoria, BC: Victoria Transport Policy Institute. Retrieved from http://www.vtpi.org/avip.pdf

Litman, T. (2017b). Socially optimal transport prices and markets. Victoria, BC: Victoria Transport Policy Institute. Retrieved from http://www.vtpi.org/sotpm.pdf

López-Camacho, E., Ochoa, G., Terashima-Marín, H., \& Burke, E. K. (2013). An effective heuristic for the two-dimensional irregular bin packing problem. Annals of Operations Research, 206(1), 241-264. doi:10.1007/s10479-013-1341-4

Louf, R., \& Barthelemy, M. (2013). Modeling the polycentric transition of cities. Physical Review Letters, 111(19), 198702. doi:10.1103/PhysRevLett. 111.198702

Martin, E., \& Shaheen, S. (2016). Impacts of car2go on vehicle ownership, modal shift, vehicle miles traveled, and greenhouse gas emissions: An analysis of five North American cities (Working Paper). Berkeley, CA: Transportation Sustainability Research Center.
Martin, G. (2007). Global motorization, social ecology and China. Area, 39(1), 66-73. doi:10.1111/j.14754762.2007.00718.x

Mohl, R. A. (2002). The interstates and the cities: Highways, housing and the freeway revolt (Research Report). Washington, DC: Poverty and Race Research Action Council. Retrieved from http:// www.prrac.org/pdf/mohl.pdf

Molina, M. J., \& Molina, L. T. (2004). Megacities and atmospheric pollution. Journal of the Air \& Waste Management Association, 54(6), 644-680. doi:10.1080/10473289.2004.10470936

Moriarty, P., \& Honnery, D. (2008). The prospects for global green car mobility. Journal of Cleaner Production, 16(16), 1717-1726. doi:10.1016/j.jclepro. 2007.10.025

Moriarty, P., \& Honnery, D. (2013). Greening passenger transport: A review. Journal of Cleaner Production, 54, 14-22. doi:10.1016/j.jclepro.2013.04.008

Naik, N., Kominers, S. D., Raskar, R., Glaeser, E. L., \& Hidalgo, C. A. (2017). Computer vision uncovers predictors of physical urban change. Proceedings of the National Academy of Sciences, 114(29), 7571-7576. doi:10.1073/pnas.1619003114

National Association of City Transportation Officials. (2017). Designing for all ages \& abilities. New York: NACTO. Retrieved from https://nacto.org/ 2017/12/06/designing-for-all-ages-and-abilities/

Norton, P. D. (2007). Street rivals: Jaywalking and the invention of the motor age street. Technology and Culture, 48(2), 331-359.

Organisation for Economic Co-operation and Development. (2015). Urban mobility system upgrade-How shared self-driving cars could change city traffic. Paris: OECD. Retrieved from https://www.itf-oecd. org/sites/default/files/docs/15cpb_self-drivingcars. pdf

Oja, P., Titze, S., Bauman, A., de Geus, B., Krenn, P., Reger-Nash, B., \& Kohlberger, T. (2011). Health benefits of cycling: A systematic review. Scandinavian Journal of Medicine \& Science in Sports, 21(4), 496-509. doi:10.1111/j.1600-0838.2011.01299.x

Peterson, G. D., Cumming, G. S., \& Carpenter, S. R. (2003). Scenario planning: A tool for conservation in an uncertain world. Conservation Biology, 17(2), 358-366. doi:10.1046/j.1523-1739.2003.01491.x

Piock, W., Hoffmann, G., Berndorfer, A., Salemi, P., \& Fusshoeller, B. (2011). Strategies towards meeting future particulate matter emission requirements in homogeneous gasoline direct injection engines. SAE International Journal of Engines, 4(1), 1455-1468. doi:10.4271/2011-01-1212.

Pucher, J., \& Buehler, R. (2016). Safer cycling through improved infrastructure. American Journal of Public Health, 106(12), 2089-2091. doi:10.2105/ AJPH.2016.303507

Quattrone, G., Capra, L., \& De Meo, P. (2015). There's no such thing as the perfect map: Quantifying bias in 
spatial crowd-sourcing datasets. Proceedings of the 18th ACM conference on computer supported cooperative work \& social computing, (pp. 1021-1032). New York: ACM.

Quercia, D., O'Hare, N. K., \& Cramer, H. (2014). Aesthetic capital: What makes London look beautiful, quiet, and happy? In Proceedings of the 17th ACM conference on computer supported cooperative work \& social computing, (pp. 945-955). New York: ACM.

Ratti, C., \& Biderman, A. (2017). From parking lot to paradise. Scientific American, 317(1), 54-59. doi:10.1038/scientificamerican0717-54

Resch, B., Summa, A., Zeile, P., \& Strube, M. (2016). Citizen-centric urban planning through extracting emotion information from Twitter in an interdisciplinary space-time-linguistics algorithm. Urban Planning, 1(2), 114-127. doi:10.17645/up.v1i2.617

Reynolds, C. C., Harris, M. A., Teschke, K., Cripton, P. A., \& Winters, M. (2009). The impact of transportation infrastructure on bicycling injuries and crashes: A review of the literature. Environmental Health, 8(1), 47. doi:10.1186/1476-069X-8-47

Salesses, P., Schechtner, K., \& Hidalgo, C. A. (2013). The collaborative image of the city: Mapping the inequality of urban perception. PloS one, 8(7), e68400. doi:10.1371/journal.pone.0068400

Santi, P., Resta, G., Szell, M., Sobolevsky, S., Strogatz, S. H., \& Ratti, C. (2014). Quantifying the benefits of vehicle pooling with shareability networks. Proceedings of the National Academy of Sciences, 111(37), 1329013294. doi:10.1073/pnas.1403657111

Senaratne, H., Mobasheri, A., Ali, A. L., Capineri, C., \& Haklay, M. (2017). A review of volunteered geographic information quality assessment methods. International Journal of Geographical Information Science, 31(1), 139-167. doi:10.1080/13658816. 2016.1189556

Shaheen, S., \& Cohen, A. (2007). Growth in worldwide carsharing: An international comparison. Transportation Research Record: Journal of the Transportation Research Board, (1992), 81-89. doi:10.3141/1992-10

Shoup, D. C. (2005). The high cost of free parking. Chicago: Planners Press.

Speck, J. (2013). Walkable city: How downtown can save America, one step at a time. Basingstoke, UK: Macmillan.

Spieser, K., Treleaven, K., Zhang, R., Frazzoli, E., Morton, D., \& Pavone, M. (2014). Toward a systematic approach to the design and evaluation of automated mobility-on-demand systems: A case study in Singapore. In G. Meyer \& S. Beiker (Eds.), Road vehicle au- tomation (pp. 229-245). Cham: Springer.

Tachet, R., Santi, P., Sobolevsky, S., Reyes-Castro, L. I., Frazzoli, E., Helbing, D., \& Ratti, C. (2016). Revisiting street intersections using slot-based systems. PloS one, 11(3), e0149607. doi:10.1371/journal.pone. 0149607

Teschke, K., Harris, M. A., Reynolds, C. C., Winters, M., Babul, S., Chipman, M., . . . Cripton, P. A. (2012). Route infrastructure and the risk of injuries to bicyclists: a case-crossover study. American Journal of Public Health, 102, 2336-2343.

Ulbrich, F., Rotter, S. S., \& Rojas, R. (2016). Adapting to the traffic swarm: Swarm behaviour for autonomous cars. In Y. Tan (Ed.), Handbook of research on design, control, and modeling of swarm robotics (pp. 263-285). Hershey, PA: IGI Global.

Urry, J. (2013). Societies beyond oil: Oil dregs and social futures. London: Zed Books.

Wainer, H. (2005). Graphic discovery: A trout in the milk and other visual adventures. Princeton University Press.

Wang, Y., Sperling, D., Tal, G., \& Fang, H. (2017). China's electric car surge. Energy Policy, 102, 486-490. doi:10.1016/j.enpol.2016.12.034

Weigele, S. (2014) . Urbane Mobilität im Umbruch? Hamburg: civity Management Consultants. Retrieved from http://www.civity.de/de/publikationen/2014/ 08/matters_no_1_-_urbane_mobilit\%C3\%A4t_im_ umbruch

Weinberger, R., Seaman, M., Johnson, C., \& Kaehny, J. (2008). Guaranteed parking-Guaranteed driving. New York: Transportation Alternatives.

Winters, M., Babul, S., Becker, H. J. E. H., Brubacher, J. R., Chipman, M., Cripton, P., . . Monro, M. (2012). Safe cycling: how do risk perceptions compare with observed risk. Canadian Journal of Public Health, 103(9), S42-7.

World Economic Forum. (2016). Understanding the sharing economy. Cologny, Switzerland: World Economic Forum.

World Health Organization. (2015). Global status report on road safety 2015. Geneva, Switzerland: WHO.

World Health Organization. (2017). World health statistics 2017. Geneva, Switzerland: WHO.

Zhang, H., \& Malczewski, J. (2017). Quality evaluation of volunteered geographic information: The case of OpenStreetMap. In In C. E. C. Campelo, M. Bertolotto, \& P. Corcoran (Eds.), Volunteered geographic information and the future of geospatial data (pp. 19-46). Hershey, PA: IGI Global. 


\section{About the Author}

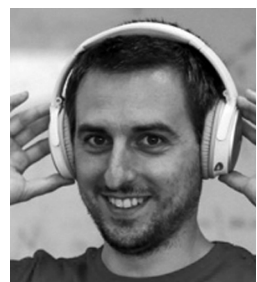

Michael Szell is Assistant Professor at Central European University (Center for Network Science), Adjunct Visiting Professor at Northeastern University (Center for Complex Network Research), External Faculty at the Complexity Science Hub Vienna, and Researcher at the Hungarian Academy of Sciences. He was part of the development team of What the Street!? (whatthestreet.moovellab.com) as researcher in residence at moovel lab. His research focuses on quantifying human behavior and social networks, urban sustainability and mobility, with a particular focus on data visualization. 